\title{
Anti-inflammatory effects on ischemia/reperfusion-injured lung transplants by the cluster of differentiation 26/ dipeptidylpeptidase 4 (CD26/DPP4) inhibitor vildagliptin
}

Jae-Hwi Jang, PhD, ${ }^{a}$ Yoshito Yamada, MD, PhD, ${ }^{a}$ Florian Janker, MSc, ${ }^{a}$ Ingrid De Meester, $\mathrm{PhD}$, Lesley Baerts, $\mathrm{PhD},{ }^{\mathrm{b}}{ }^{\mathrm{G}}$ Gwendolyn Vliegen, MSc, ${ }^{\mathrm{b}}$ Ilhan Inci, MD, ${ }^{\mathrm{a}}$ Shampa Chatterjee, PhD,

Walter Weder, $\mathrm{MD},{ }^{\mathrm{a}}$ and Wolfgang Jungraithmayr, $\mathrm{MD}, \mathrm{PhD}^{\mathrm{a}}$

\section{ABSTRACT}

Objectives: We showed previously that stromal cell-derived factor 1 (SDF-1) is a substrate of cluster of differentiation 26/dipeptidylpeptidase 4 (CD26/DPP4) and exerts regenerative properties on acute lung ischemia-reperfusion injury on CD26/DPP4 inhibition. Here, we extend our studies to test whether an intermediate recovery of lung transplants from ischemia/reperfusion injury by CD26/DPP4 inhibition can be achieved for up to 14 days.

Methods: Syngeneic mouse lung transplantation (Tx) was performed in C57BL/6 and in CD26-/- mice by applying 18 hours of cold ischemia. Donor lungs were preconditioned with saline or the CD26/DPP4 inhibitor vildagliptin $(1 \mu \mathrm{g} / \mathrm{mL}$ [3 $\mu \mathrm{M}]$ ]). In vitro, the influence of vildagliptin and SDF-1 on the macrophage cell line RAW 264.7 was tested. Transplants were analyzed up to 14 days after Tx for the expression of SDF-1, tumor necrosis factor- $\alpha$ (TNF- $\alpha$ ), interleukin-10, intercellular adhesion molecule-1 (ICAM-1), immune cell infiltration, and oxygenation.

Results: Cold ischemic time of 18 hours with vildagliptin preconditioning elevated lung SDF-1 levels $(P=.0011)$ and increased interleukin-10-producing macrophages $(P=.0165)$ compared with the control. SDF-1 reduced macrophage-derived TNF- $\alpha(P=.0248)$ in vitro. Five hours after Tx, vildagliptin significantly reduced macrophages and neutrophils $(P=.0306)$, decreased ICAM-1 expression $(P=.002)$, and improved transplant oxygenation $(P=.0181)$. Seven days after Tx, grafts were preserved on CD26/DPP4inhibition: perivascular macrophages $(P=.0046)$ and TNF- $\alpha(P=.0013)$ were reduced as well as T and B cells. ICAM-1 was absent in CD26/DPP4-inhibited grafts at all time points.

Conclusions: This study proves an intermediate improvement of ischemia/ reperfusion-injured lung transplants by the CD26/DPP4-inhibitor vildagliptin up to 14 days. Enhanced levels of SDF-1 induced an anti-inflammatory effect on a cellular and protein level, and render CD26/DPP4 inhibition preconditioning effective for the protection from lung ischemia/reperfusion injury. (J Thorac Cardiovasc Surg 2017;153:713-24)

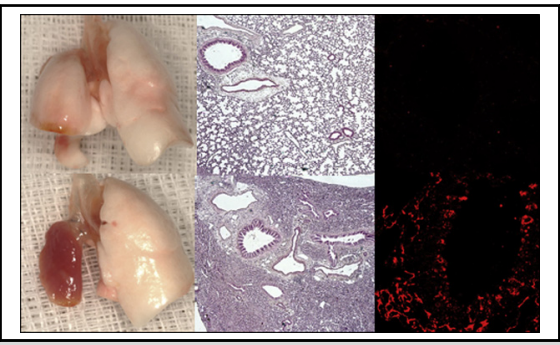

Vildagliptin induces intermediate lung transplant improvement from ischemia/reperfusion injury.

Central Message

Preconditioning with the cluster of differentiation 26/dipeptidylpeptidase 4 inhibitor vildagliptin proved to be effective for an attenuation of ischemia/reperfusion injury up to 14 days.

Perspective

Preconditioning with the cluster of differentiation 26/dipeptidylpeptidase 4 inhibitor vildagliptin provides intermediate improvement of lung transplants from ischemia/reperfusion injury for up to 14 days. Proposed effector mechanisms are enhanced interleukin-10-producing macrophages, reduced adhesion molecules, and reduced immune cells infiltration. We suggest vildagliptin as an effective compound for donor lung preconditioning for the attenuation of ischemia/reperfusion injury.

See Editorial Commentary page 725.

See Editorial page 711.

\footnotetext{
From the ${ }^{\mathrm{a}}$ Division of Thoracic Surgery, University Hospital Zurich, Zurich, Switzerland; ${ }^{\mathrm{b}}$ Laboratory of Medical Biochemistry, Department of Pharmaceutical Sciences, University of Antwerp, Antwerp, Belgium; and ${ }^{\mathrm{c} I n s t i t u t e}$ for Environmental Medicine and Department of Physiology, University of Pennsylvania Perelman School of Medicine, Philadelphia, Pa.

Supported by the Suisse National Foundation (SNF) 2010 (310030_130824/1), by a "Matching Fund" of the University Zurich 2011 (DFL_MF 1134), by the "Hartmann-Müller Stiftung" 2012, Zurich, Switzerland (Ges.-Nr. 1591), and by a GOA grant (2015-2018), University of Antwerp.
}

Drs Jang and Yamada contributed equally to this study.

Received for publication April 26, 2016; revisions received Oct 25, 2016; accepted for publication Oct 27, 2016; available ahead of print Dec 7, 2016.

Address for reprints: Wolfgang Jungraithmayr, MD, PhD, Division of Thoracic Surgery University Hospital Zurich Raemistr, 1008091 Zurich, Switzerland (E-mail: wolfgang.jungraithmayr@usz.ch).

$0022-5223 / \$ 36.00$

Copyright (C) 2016 by The American Association for Thoracic Surgery

http://dx.doi.org/10.1016/j.jtcvs.2016.10.080 


$$
\begin{aligned}
& \text { Abbreviations and Acronyms } \\
& \begin{aligned}
\text { CD26/DPP4 }= & \text { cluster of differentiation } \\
& \text { 26/dipeptidylpeptidase } 4 \\
\text { CI } & =\text { cold ischemia } \\
\text { ELISA } & \text { enzyme-linked immunosorbent } \\
& \text { assay } \\
\text { FACS } & =\text { fluorescence-activated cell sorting } \\
\text { HRP } & =\text { horseradish peroxidase } \\
\text { ICAM-1 } & =\text { intercellular adhesion molecule-1 } \\
\text { IL-10 } & =\text { interleukin-10 } \\
\text { I/R } & =\text { ischemia/reperfusion } \\
\text { NE } & =\text { neutrophil elastase } \\
\text { SDF-1 } & =\text { stromal cell }- \text { derived factor } 1 \\
\text { TNF- } \alpha & =\text { tumor necrosis factor- } \alpha \\
\text { Tx } & =\text { transplantation }
\end{aligned}
\end{aligned}
$$

\section{Scanning this QR code will take you to the supplemental figures and video for this article.}

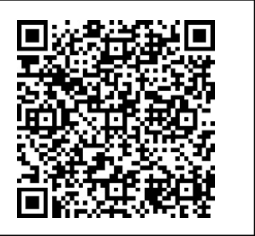

The cluster of differentiation 26/dipeptidylpeptidase 4 (CD26/DPP4) is a transmembrane molecule that is expressed on activated $\mathrm{T}$ and $\mathrm{B}$ cells as well as on epithelial and endothelial cells of various organs, including the lung. ${ }^{1}$ CD26/DPP4 functions both as a co-stimulatory molecule for $\mathrm{T}$ cells and has exopeptidase activity via an extramembranous catalytic domain. Yet, the physiologic functionality of CD26/DPP4 hinges on both. ${ }^{2-4}$ Several key cytokines, chemokines, and neuropeptides are susceptible to DPP4 cleavage. ${ }^{3,5}$ One such is chemokine stromal cell-derived factor- 1 (SDF-1), ${ }^{6}$ a key peptide for the recruitment and homing of bone marrow-derived regenerative stem cells. ${ }^{7}$

We have shown recently that the treatment of a mouse lung transplant recipient with a CD26/DPP4 inhibitor (vildagliptin) enhanced the levels of SDF-1 within transplanted lungs. Increased SDF-1 resulted in increased regenerative progenitor cell infiltration of the engrafted organ and recovery from ischemia/reperfusion (I/R) injury at 48 hours after transplantation (Tx). ${ }^{8}$ This was the first proof that CD26/DPP4 inhibition can indeed improve I/R injury via SDF-1-mediated effects. Our findings, however, were limited to 48 hours post-Tx, a short time range that usually is chosen by the majority of researchers for the investigation of I/R injury. This short time period, however, does not provide the proof for a definite and sustained benefit and function of the graft. Short-term recovery from I/R injury seems to be only beneficial when there is a long-term functionality of the transplant, but the evidence from the literature is scarce with regard to a sustained attenuation of $\mathrm{I} / \mathrm{R}$ injury.

To fill this gap of knowledge and to test whether a longer protective effect by CD26/DPP4-inhibition and its substrate SDF-1 can be achieved, we here evaluated the treatment with the CD26/DPP4 inhibitor vildagliptin for up to 14 days on I/R-injured lungs. To this end, we preconditioned the organ with vildagliptin and analyzed the function and morphology of the engrafted organ immediately after cold ischemia (CI), as well as 5 hours, 7 days, and 14 days after orthotopic mouse single-lung Tx.

\section{MATERIALS AND METHODS \\ Animals}

Male wild-type (C57BL/6; Charles River, Germany) mice were used for all experiments. Breeders of CD26-/- mouse (on a C57BL/6 background) were obtained from Taconic (Taconic, Bomholt, Denmark) with approval from Dr D. Marguet (Centre d'Immunologie de Marseille Luminy-INSERM, Marseille Luminy, France). Animals were fed a standard diet with water and food ad libitum and were kept under constant environmental conditions. They received adequate care in strict accordance with the Principles of Laboratory Animal Care (National Institutes of Health Publication No. 85-23, promulgated in 1985, most recently revised in 1996).

\section{Experimental Setup for Mouse Lung Tx}

Orthotopic left single-lung $\mathrm{Tx}$ between a syngeneic mouse strain (C57BL/6) was performed as we described in detail previously (Video 1). ${ }^{9}$ Donor grafts were exposed to 18 hours of CI time before Tx with or without intragraft preconditioning by vildagliptin $(1 \mu \mathrm{g} / \mathrm{mL}$ in saline: custom synthesized by GLSynthesis, Inc, Worcester, Mass). Preconditioning of the donor organ was accomplished by perfusing the aforementioned solution via the pulmonary artery during organ recovery as we usually do for regular donor organ perfusion. To avoid a remote effect

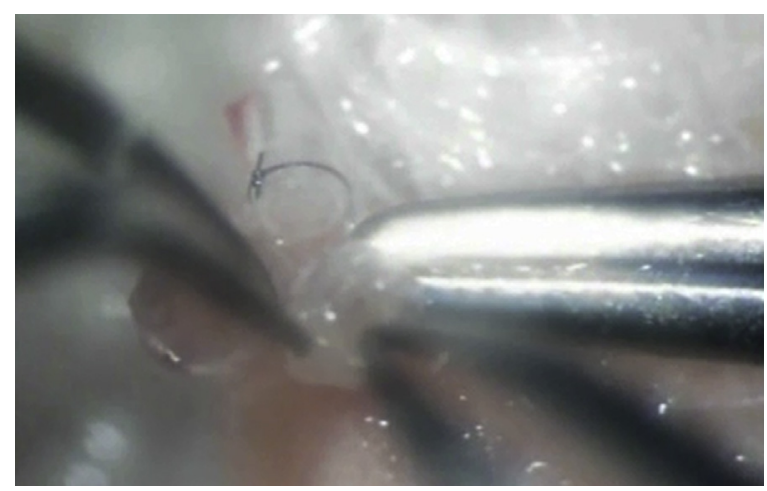

VIDEO 1. Orthotopic left single lung transplantation: preparing of the hilar structures of the left donor lung (artery, bronchus, and vein), dissecting them from each other and equipping them with a plastic cuff. This prepared donor lung will then be implanted into the recipient by introducing the cuffed donor structures into the respective recipient artery, bronchus, and vein. After opening the newly formed anastomoses, a functional lung transplant is available for post-transplant analyses. Video available at: http://www.jtcvsonline.org/article/S0022-5223(16)31488-X/ addons. 
in the contralateral lung of the recipient after surgery, naïve mouse lungs were used to obtain the baseline values.

After 18 hours of preconditioning, the lungs did not have any further exposure to vildagliptin. All experimental lungs subsequently were harvested at 4 time points and assessed according to each experiment: (1) 18 hours of cold storage of nontransplanted lung (control $[n=5]$ vs vildagliptin $[\mathrm{n}=5]$ ); (2) 5 hours after Tx (control $[\mathrm{n}=5]$ vs vildagliptin $[\mathrm{n}=5]$ ); 7 days after Tx (control $[\mathrm{n}=8]$ vs vildagliptin $[\mathrm{n}=7]$ vs CD26-/- $[n=4]) ; 14$ days after Tx (control $[n=5]$ vs vildagliptin $[n=5])$.

To achieve proper measurements by scientific means, we used the samples from repeated experiments for the assessments of SDF-1 and interleukin-10 (IL-10; $\mathrm{n}=3$ for both control and vildagliptin groups) as well as fluorescence-activated cell sorting (FACS) analysis ( $\mathrm{n}=3$ for naïve, $\mathrm{n}=5$ for control and vildagliptin). We repeated the same experiment separately to assess different values of interested. The relevant information for the number of samples of each experiment is described detailed in the figure legends. During each time point of harvest, plasma samples were analyzed for tumor necrosis factor- $\alpha$ (TNF- $\alpha$ ) measurement. All experimental Tx procedures were performed at the microsurgical laboratory of the Division of Thoracic Surgery at University Hospital Zurich.

\section{Histology and Immunohistochemistry}

Formalin-fixed and paraffin-embedded samples were stained by hematoxylin and eosin staining. Immunohistochemistry was performed on the samples at 5 hours after Tx ( $\mathrm{n}=5$ for control and vildagliptin groups), 7 days ( $\mathrm{n}=5$ for control and vildagliptin groups, $\mathrm{n}=4$ for CD26-/- group), and 14 days ( $\mathrm{n}=4$ for control and vildagliptin groups) after Tx to stain CD3 (antibody dilution: 1:100, rabbit horseradish peroxidase [HRP]; Diagnostic Biosystems, Muttenz, Switzerland), B220 (antibody dilution: 1:8000, Rat IgG HRP; Pharmingen, Becton Dickinson, Allschwil, Switzerland), neutrophil elastase (NE) (antibody dilution: 1:2000, Rabbit HRP; Abcam Ltd, Cambridge, UK), and F4/80 (antibody dilution: 1:300, Rat IgG HRP; BMA Biomedicals AG, Augst, Switzerland). Positively stained cells were counted in a perivascular or alveolar region at the indicated magnification.

\section{Expression of Intercellular Adhesion Molecule-1 (ICAM-1) by Immunofluorescence}

ICAM-1 antibody was obtained commercially (Abcam, Cambridge, Mass). Donor grafts were embedded in paraffin, and sections were deparaffinized in xylene followed by treatment in $100 \%$ ethanol, $95 \%$ ethanol, $80 \%$ ethanol, and $50 \%$ ethanol (5 minutes, 2 times each). Tissue sections were then rinsed with water and $1 \times$ phosphate-buffered saline buffer. Antigen retrieval was performed by boiling in antigen unmasking solution (Vector Laboratories, Inc, Burlingame, Calif) for 30 minutes followed by cooling the samples to room temperature.

Tissue sections were washed and permeabilized and then stained for ICAM-1 (1:200). Tissue sections from each experimental time points including 18 hours of CI ( $\mathrm{n}=3$ for control and vildagliptin groups), 7 days $(\mathrm{n}=5$ for control and vildagliptin groups), and 14 days $(\mathrm{n}=3$ for control and vildagliptin groups) after Tx were used and the fluorescent signal from 5 regions within each sample were evaluated. Images were acquired with a Zeiss Meta 510 laser scanning confocal and multiphoton microscope with Zeiss 2007 software (Zeiss, Inc, Thornwood, NY). All immunofluorescence analyses were performed at the Institute for Environmental Medicine and Department of Physiology, University of Pennsylvania Perelman School of Medicine (Philadelphia, Pa).

\section{Analysis of Protein Expression}

Samples were homogenized in lysis buffer containing a protease inhibitor cocktail (Roche Diagnostics GmbH, Mannheim, Germany), phosphatase inhibitor cocktail 3, $50 \mathrm{mM}$ Tris, $150 \mathrm{mM} \mathrm{NaCl}, 5 \mathrm{mM}$ ethylenediaminetetraacetic acid, and $0.5 \%$ NP-40 (Sigma-Aldrich, Buchs, Switzerland). Protein concentration was determined with the Bradford protein assay (BioRad,
Hercules, Calif). The expressions of TNF- $\alpha$, SDF-1, and IL-10 were assessed by enzyme-linked immunosorbent assay (ELISA; R\&D Systems, Abingdon, United Kingdom). For ICAM- 1 western blotting ( $4 \%-20 \%$ gradient gel, antibody dilution: 1:2000), reducing sodium dodecyl sulfate polyacrylamide gel electrophoresis was performed and samples ( $\mathrm{n}=3$ for control, $\mathrm{n}=4$ for vildagliptin) were blotted onto a polyvinylidene fluoride membrane. After secondary antibody binding, the detection was performed according to standard protocols with the ECL detection reagent (BioRad).

\section{Assay for Enzymatic Activity of DPP4}

DPP4-like enzymatic activity was measured in the tissue lysate from control $(n=5)$ and vildagliptin $(n=5)$ groups after 18 hours of CI with the use of glycyl-prolyl-4-methoxy- $\beta$-naphthylamide. To summarize, in a 96 -well plate, $10-\mu \mathrm{L}$ samples were mixed with $0.5 \mathrm{mM}$ glycyl-prolyl-4-methoxy- $\beta$-naphthylamide in $50 \mathrm{mM}$ Tris buffer, $\mathrm{pH} 8.3$, in a final volume of $110 \mu \mathrm{L}$. DPP4-like activity was determined kinetically for 20 minutes at $37^{\circ} \mathrm{C}$ via measurement of the velocities of 4-Me- $\beta$-NA release $(\lambda \mathrm{ex}=340 \mathrm{~nm}, \lambda \mathrm{em}=430 \mathrm{~nm})$ from the substrate (all reagents are from Sigma-Aldrich, Buchs, Switzerland).

\section{Oxygen Saturation In Vivo}

The functionality of the (transplanted) lung was evaluated by the measurement of saturated oxygen $\left(\mathrm{PaO}_{2} / \mathrm{FiO}_{2}\right.$ ratio $)$ level in arterial blood samples. Blood samples were taken from the abdominal aorta $(100 \mu \mathrm{L})$ for blood gas analysis and electrolyte measurement test (Epocal, Inc, Ottawa, Ontario, Canada) on respective reperfusion time points ( 5 hours $[\mathrm{n}=5$ for control and vildagliptin groups], 7 days [ $\mathrm{n}=3$ for control and vildagliptin groups], and 14 days $[\mathrm{n}=5$ for control and vildagliptin groups] after Tx) immediately before harvesting of the animal. The reason for not being able to take blood from the pulmonary vein is that transplant recipients do not tolerate occlusion of the contralateral lung. For the scientific validation of the method, we compared the experimental data with the values of normal naive mice.

\section{Fluorescence-Activated Cell Sorting}

Single-cell suspensions from mouse lungs of naïve $(\mathrm{n}=3), 18$ hours of $\mathrm{CI}$ control $(\mathrm{n}=5)$, and vildagliptin $(\mathrm{n}=5)$ groups were prepared as described previously. ${ }^{10}$ In summary, lungs were cut and incubated in collagenase II ( $2 \mathrm{mg} / \mathrm{mL}$ : PAN Biotech, Aidenbach, Germany) solution ( $10 \%$ fetal bovine serum, $50 \mu \mathrm{g} / \mathrm{mL}$ gentamicin in RPMI 1640) for 30 minutes at $37^{\circ} \mathrm{C}$. The collagenase reaction was stopped by adding $1 \mathrm{~mL}$ of $1 \mathrm{M}$ ethylenediaminetetraacetic acid, and cells were then filtered through a $70-\mu \mathrm{m}$ cell strainer. Antibodies for IL10-APC, F4/80-PE, CD4-FITC, CD8-PerCP, and NKp46Alexa647 (all antibodies from BD Pharmingen, Allschwil, Switzerland) were used and subjected to flow cytometry with the BD FACSCanto II flow cytometer (BD Biosciences, San Jose, Calif).

\section{In Vitro Analysis of SDF-1 Effect on Macrophage Activation}

RAW 264.7 mouse macrophage cell line was maintained in Dulbecco's Modified Eagle Medium containing 10\% fetal bovine serum, penicillin $(120 \mu \mathrm{g} / \mathrm{mL}) / \mathrm{streptomycin}(200 \mu \mathrm{g} / \mathrm{mL})$. The cell line was seeded into 10 -cm plates to reach $70 \%$ confluence. Two days after cell seeding, media were changed to serum-free conditions. Twelve hours later, cells were exposed to different concentrations of SDF-1 (0.1-100 ng/mL; R\&D systems, Abingdon, United Kingdom). The supernatant was collected at $1,3,6,12,24$, and 48 hours after SDF- 1 treatment to measure TNF- $\alpha$ release. This experiment was repeated 3 times.

\section{Statistical Analysis}

Data are presented as means \pm SD. Groups were compared with the Student $t$ test for unpaired samples with Prism 4.0 (GraphPad Software, San Diego, Calif). A 2-sided $P$-value $<.05$ was considered as statistically significant. 
DPP4-like activity

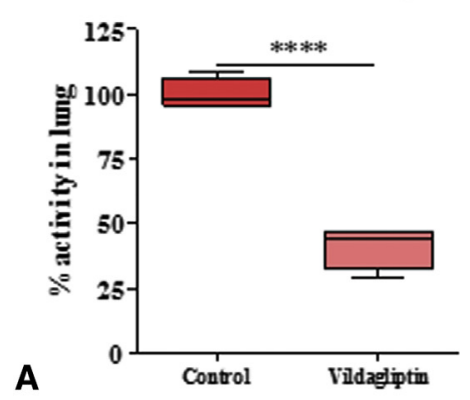

A

II- $10^{+}$macrophages

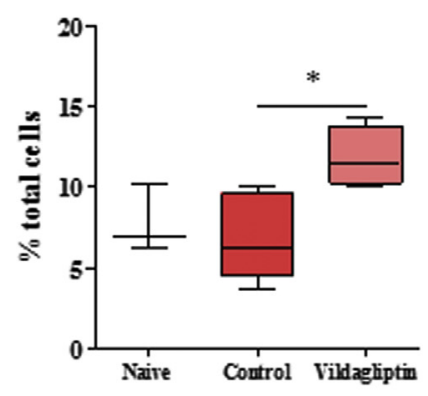

D

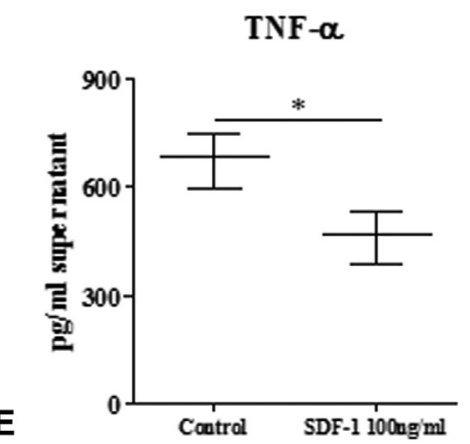

E
SDF-1

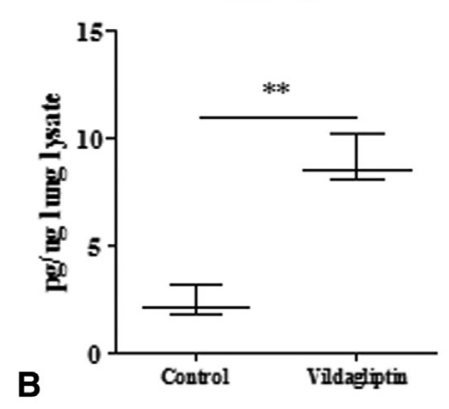

18 hours CI

+ Saline



IL-10

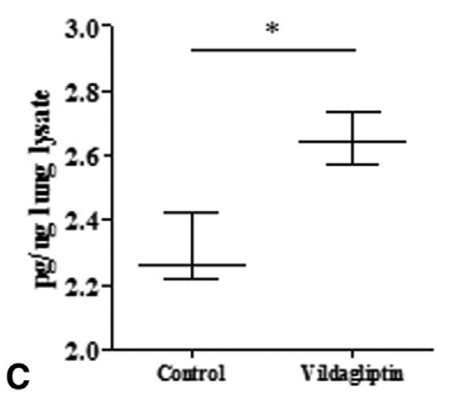

18 hours CI

+Vildagliptin

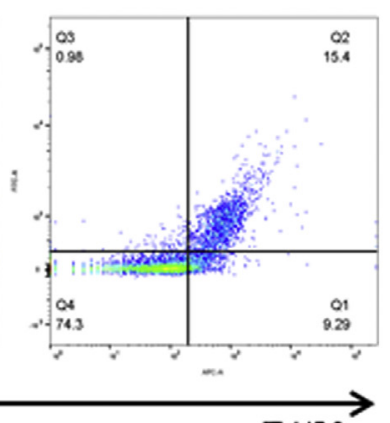

F4/80

FIGURE 1. Anti-inflammatory effect of the CD26/DPP4 substrate SDF-1 on macrophages after 18 hours of CI. Vildagliptin-preconditioned grafts showed significantly reduced DPP4-like activity after 18 hours of CI (A, control [ $\mathrm{n}=5]$, vildagliptin $[\mathrm{n}=5][* * * * P<.0001])$. Tissue levels of SDF-1 and IL-10 were increased in vildagliptin-preconditioned lungs $\left(\mathrm{B}\right.$, control $[\mathrm{n}=3]$, vildagliptin $[\mathrm{n}=3]\left[{ }^{* *} P=.0011\right]$; $\mathrm{C}$, control [n=3], vildagliptin [n $\left.=3\right]$, respectively $[* P=.0105])$. Increased numbers of IL-10-expressing macrophages were detected by flow cytometry in vildagliptin-preconditioned grafts before Tx (D, naïve [n $=3]$, control $[\mathrm{n}=5]$, vildagliptin $\left.[\mathrm{n}=5]\left[{ }^{*} P=.0165\right]\right)$. Treatment by SDF-1 decreased TNF- $\alpha$ production in the RAW 264.7 cell line $\left(\mathrm{E}\right.$, control $[\mathrm{n}=3]$, SDF-1 $\left.[\mathrm{n}=3]\left[{ }^{*} P=.0248\right]\right)$. CD26/DPP4, Cluster of differentiation 26/dipeptidylpeptidase 4; SDF-1, stromal cell-derived factor $1 ; I L-10$, interleukin-10; $C I$, cold ischemia; $T N F-\alpha$, tumor necrosis factor- $\alpha$.

\section{Quantitation of data and statistical analysis of immuno-}

fluorescence. Quantitation of the fluorescence staining was done by Image J (National Institutes of Health, Bethesda, Md) analysis software. The threshold feature of this software was used to define a selected area, and the integrated intensity was measured within that region. Data were acquired from at least 3 independent samples and expressed in arbitrary units after normalizing for equal area. Data sets were compared with the Student $t$ test, and results were considered statistically significant at $P<.05$.

\section{RESULTS}

The CD26/DPP4 Inhibitor Vildagliptin Induces Alternative Activation of Macrophages

To test the susceptibility of donor lung grafts on CD26/DPP4 and the effect of CD26/DPP4-inhibition by vildagliptin on CI injury in grafts, we analyzed the activity of CD26/DPP4, levels of SDF-1, and IL-10 by ELISA 


\section{5 hours after $T x$}
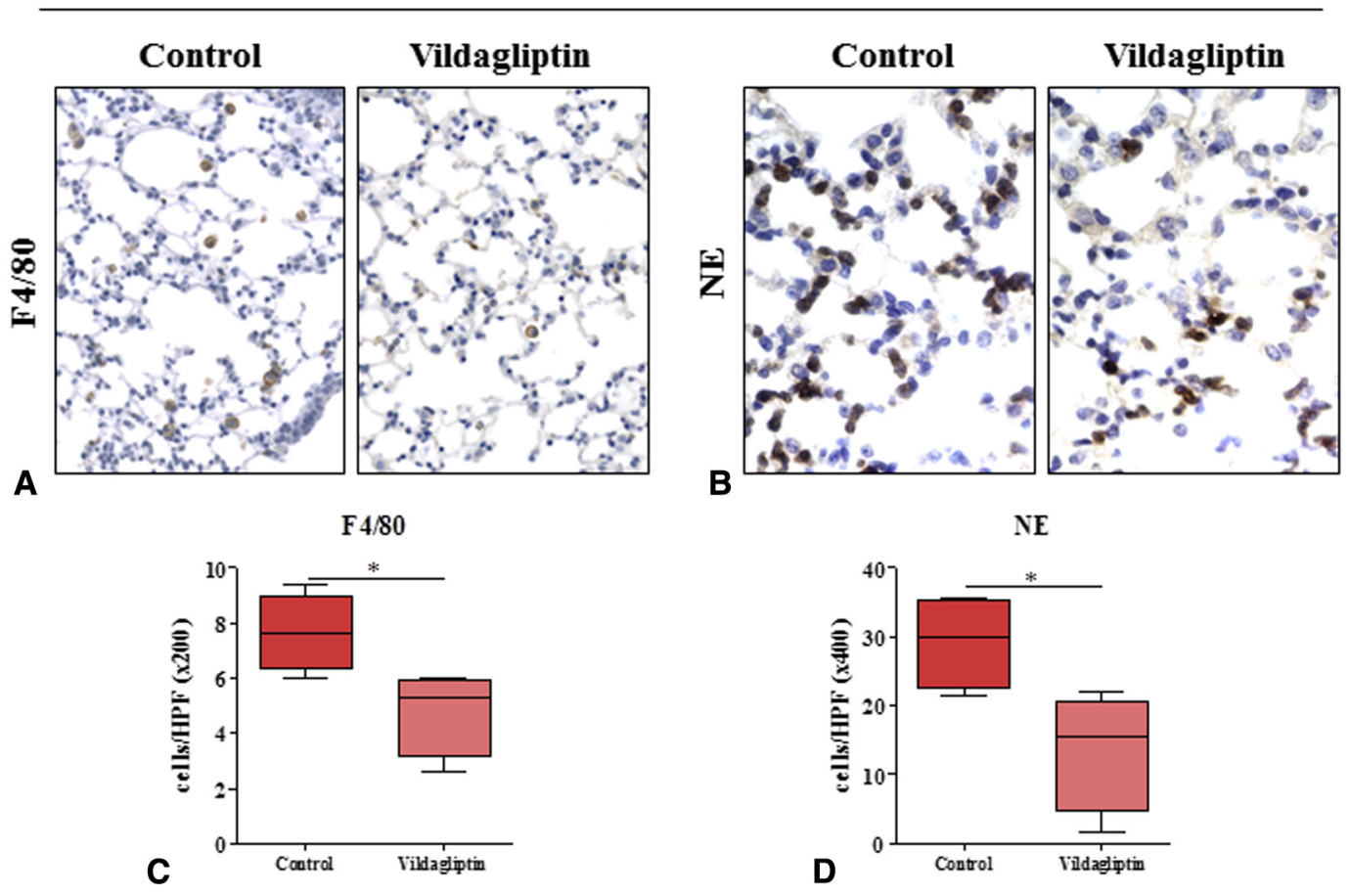

ICAM-1
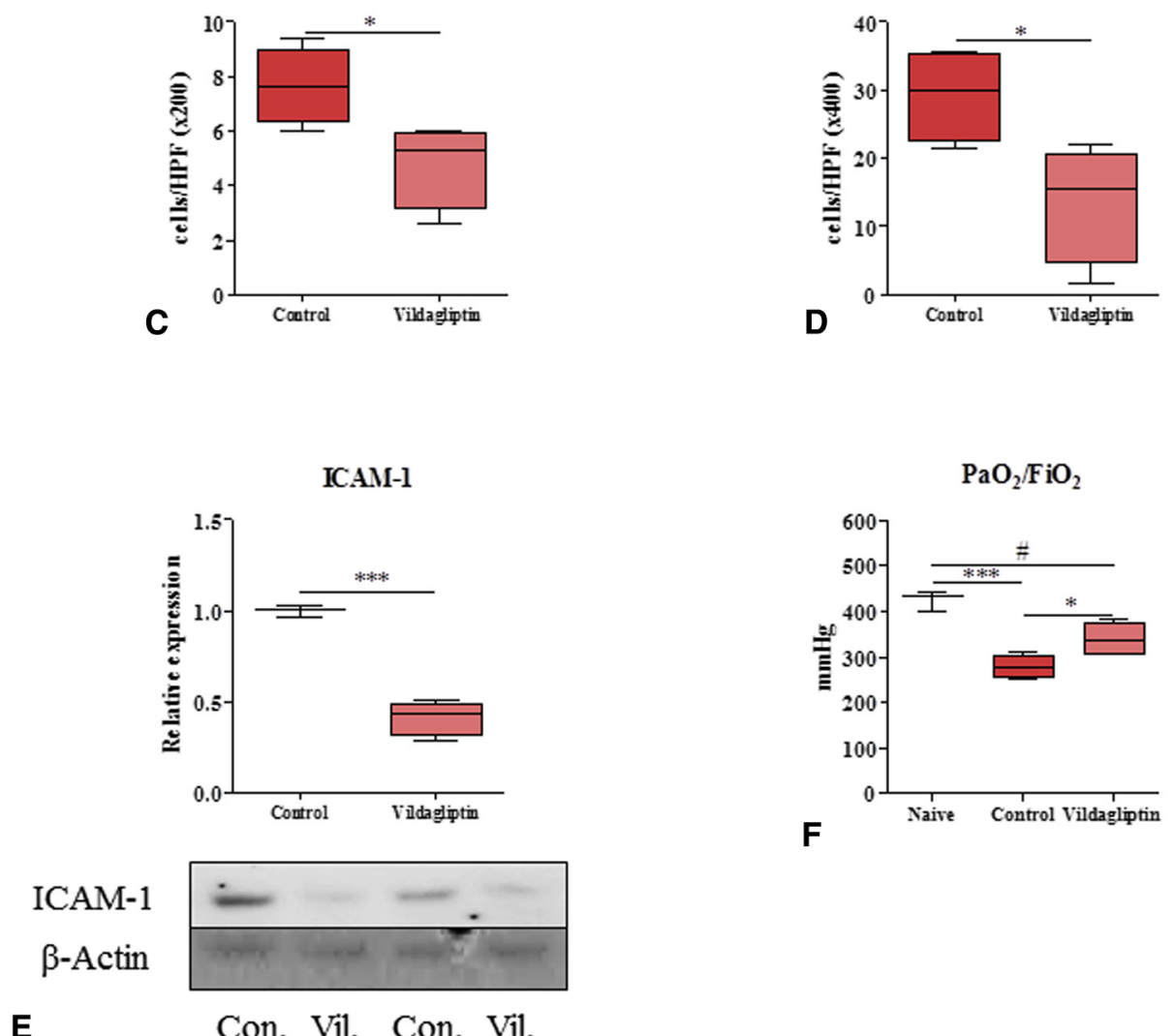

FIGURE 2. Protective effect of vildagliptin preconditioning during cold ischemia (18 hours) and during the early phase of reperfusion (5 hours) after lung Tx. The number of macrophages $(F 4 / 80+)$ and neutrophils $(N E+)$ were decreased significantly in preconditioned lungs compared with control lungs (A, $\mathrm{C},\left[{ }^{*} P=.0345\right]$ and $\mathrm{B}, \mathrm{D}[* P=.0306]$ control $[\mathrm{n}=5]$, vildagliptin $\left.[\mathrm{n}=5]\right)(\mathrm{A}, \times 200, \mathrm{~B}, \times 400)$. The expression of the adhesion molecule ICAM-1 was decreased by vildagliptin preconditioning $(\mathrm{E}$, control $[\mathrm{n}=3]$, vildagliptin $[\mathrm{n}=4] * * * P<.001)$. Saturated oxygen level improved by vildagliptin preconditioning 5 hours after lung $\mathrm{Tx}(\mathrm{F}$, näve $[\mathrm{n}=3]$, control $[\mathrm{n}=5]$, vildagliptin $[\mathrm{n}=5][* P=.0181, \# P=.0152, * * * P=.001]) . T x$, Transplantation; ICAM-1, intercellular adhesion molecule 1; Con., control; Vil., vildagliptin.

and FACS within lung tissues exposed to 18 hours' CI time. The activity of CD26/DPP4 within the lung tissue was significantly reduced by vildagliptin preconditioning (Figure 1, A). Levels of SDF-1, the substrate of CD26/DPP4, were significantly elevated 18 hours after
CI in vildagliptin-preconditioned lungs (Figure 1, B). Furthermore, vildagliptin-preconditioned lungs showed greater levels of IL-10 (Figure 1, $C$ ) measured by ELISA and also $\mathrm{IL}-10^{+}$macrophages $\left(\mathrm{F} 4 / 80^{+}\right)$compared with controls after 18 hours of CI (Figure $1, D$ ). We could 


\section{7 days after $T \mathbf{x}$}


FIGURE 3. Preserved functionality of CD26/DPP4-inhibited grafts. Seven days after lung Tx, the transplanted lungs (asterisk) showed a regular macroscopic appearance (A) by CD26/DPP4 inhibition compared with controls (asterisk), which showed a red and shrunken appearance (B). Histology showed preserved lung architecture with less cell infiltrates in CD26/DPP4-inhibited grafts (C) compared with control grafts $(\mathrm{D})(\times 25)$. Saturated oxygen levels showed trends but no difference 7 days after Tx. (E, naïve $[\mathrm{n}=3]$, control $[\mathrm{n}=3]$, vildagliptin $[\mathrm{n}=3]$, CD26-I- $[\mathrm{n}=3][* P=.0135, * * P=.005$, $\# P=.0447]$.) $T x$, Transplantation.

not find any changes of other types of cells including $\mathrm{CD} 4^{+}, \mathrm{CD}^{+}$, and $\mathrm{NKp}_{4} 6^{+}$after 18 hours of $\mathrm{CI}$ (Figure E1).

To further characterize the effect of SDF-1 on the activation of macrophages (activation of macrophages occurred spontaneously after Tx without additional stimulation), we used the macrophage cell line RAW 264.7 with increasing concentrations of SDF-1. This led to a significant reduction of TNF- $\alpha$ production at 24 hours (Figure 1,E), supporting the hypothesis of alternative macrophages activation. Summarizing these data, we provided evidence that CD26/DPP4 enhances SDF-1 availability, which leads to increased levels of IL10 -producing macrophages. This mechanism is proposed as the base for the observed results at later time points after Tx. 


\section{7 days after $\mathbf{T x}$}



Perivascular macrophage

Akeolar macrophage
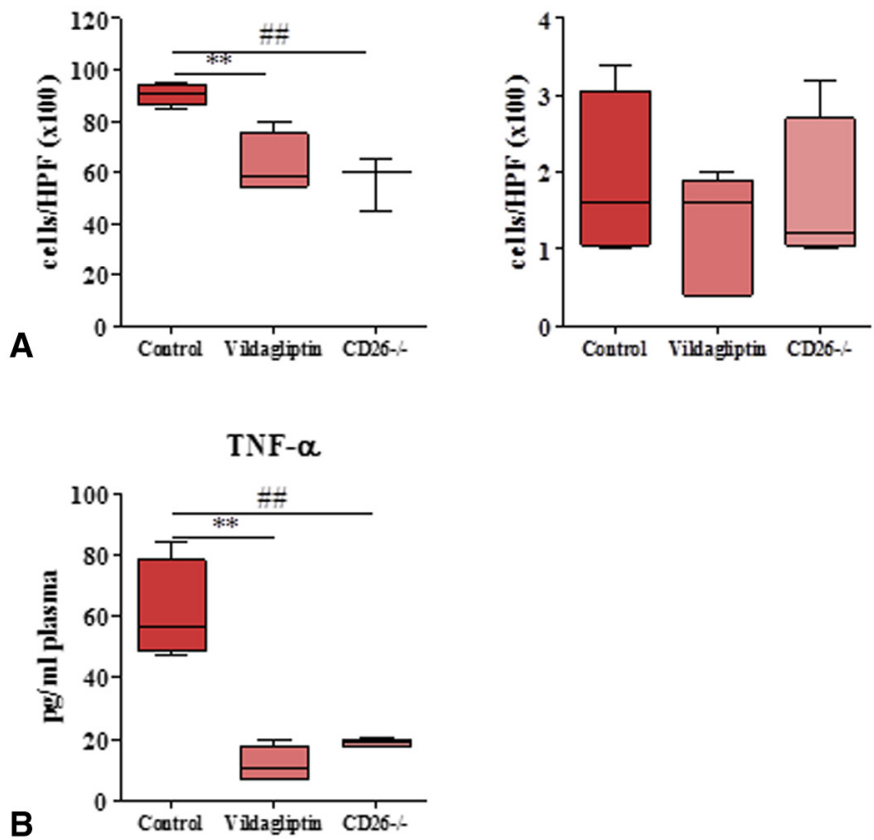

FIGURE 4. Decreased macrophage infiltration after 18 hours of CI and 7 days after lung Tx. Perivascular infiltration of macrophages was detected by F4/80 staining (A, control [ $\mathrm{n}=5]$, vildagliptin [ $\mathrm{n}=5], \mathrm{CD} 26-/-[\mathrm{n}=4][* * P=.0046$, \#\#P=.0018] [×100]). CD26/DPP4-inhibited grafts showed significantly decreased accumulation of macrophages in the perivascular space. In contrast, no significant difference in macrophage numbers could be observed in the alveolar compartment. The plasma level of the proinflammatory cytokine TNF- $\alpha$ decreased in CD26/DPP4-inhibited Tx recipients (B, control [ $\mathrm{n}=5$ ], vildagliptin [ $\left.\mathrm{n}=5], \mathrm{CD} 26-/-[\mathrm{n}=4]\left[{ }^{* *} P=.0013, \# \# P=.0021\right]\right) . T x$, Transplantation; CD26/DPP4, cluster of differentiation 26/dipeptidylpeptidase 4; $T N F-\alpha$, tumor necrosis factor- $\alpha$. 


\section{4 days after $T x$}
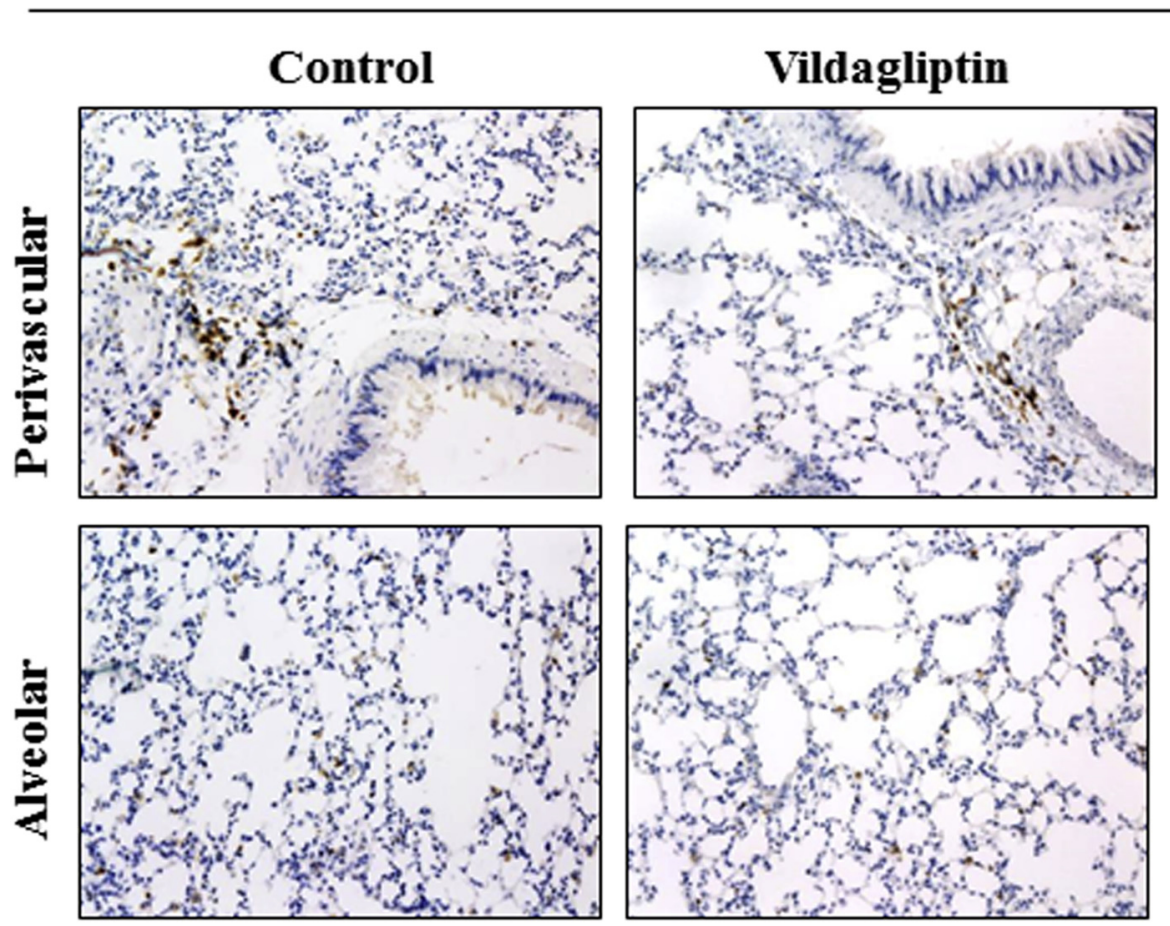

Perivascular macrophage

Alveolar macrophage


TNF- $\alpha$

$\mathrm{PaO}_{2} / \mathrm{FiO}_{2}$
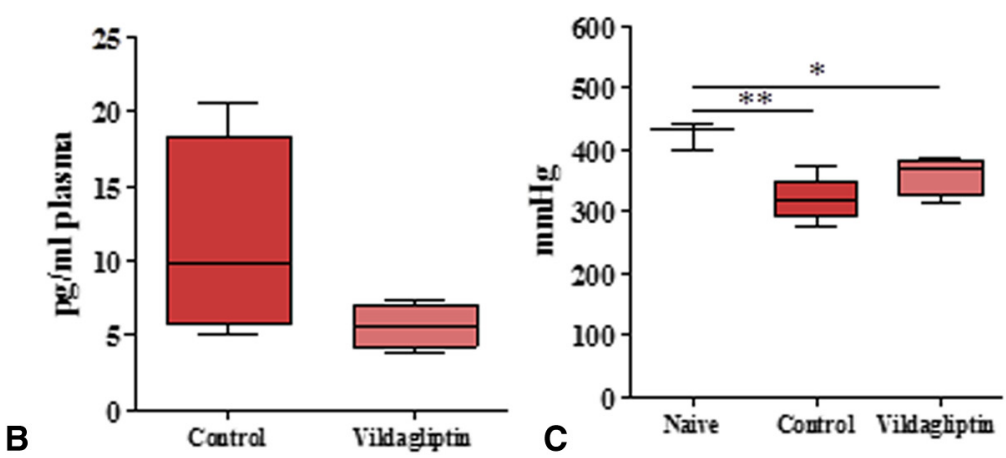

FIGURE 5. The effect of vildagliptin preconditioning on the infiltration of macrophages after 18 hours of CI and 14 days after lung Tx. $\mathrm{F} 4 / 80+$ macrophages were found in the perivascular and alveolar areas with a trend towards but no significant difference between control and vildagliptin-preconditioned grafts (A, control $[n=5]$, vildagliptin $[n=5])(\times 100)$. Plasma levels of the proinflammatory cytokine TNF- $\alpha$ were greater in control recipients compared to the vildagliptin group (B, control $[n=5]$, vildagliptin $[n=5])$. The level of saturated oxygen in the arterial blood showed a trend towards increased levels, however without reaching statistical significance $(\mathrm{C}$, control $[\mathrm{n}=5]$, vildagliptin $[\mathrm{n}=5])(* P=.0275 ; * * P=.0041)$. $T x$, Transplantation; TNF- $\alpha$, tumor necrosis factor- $\alpha$. 

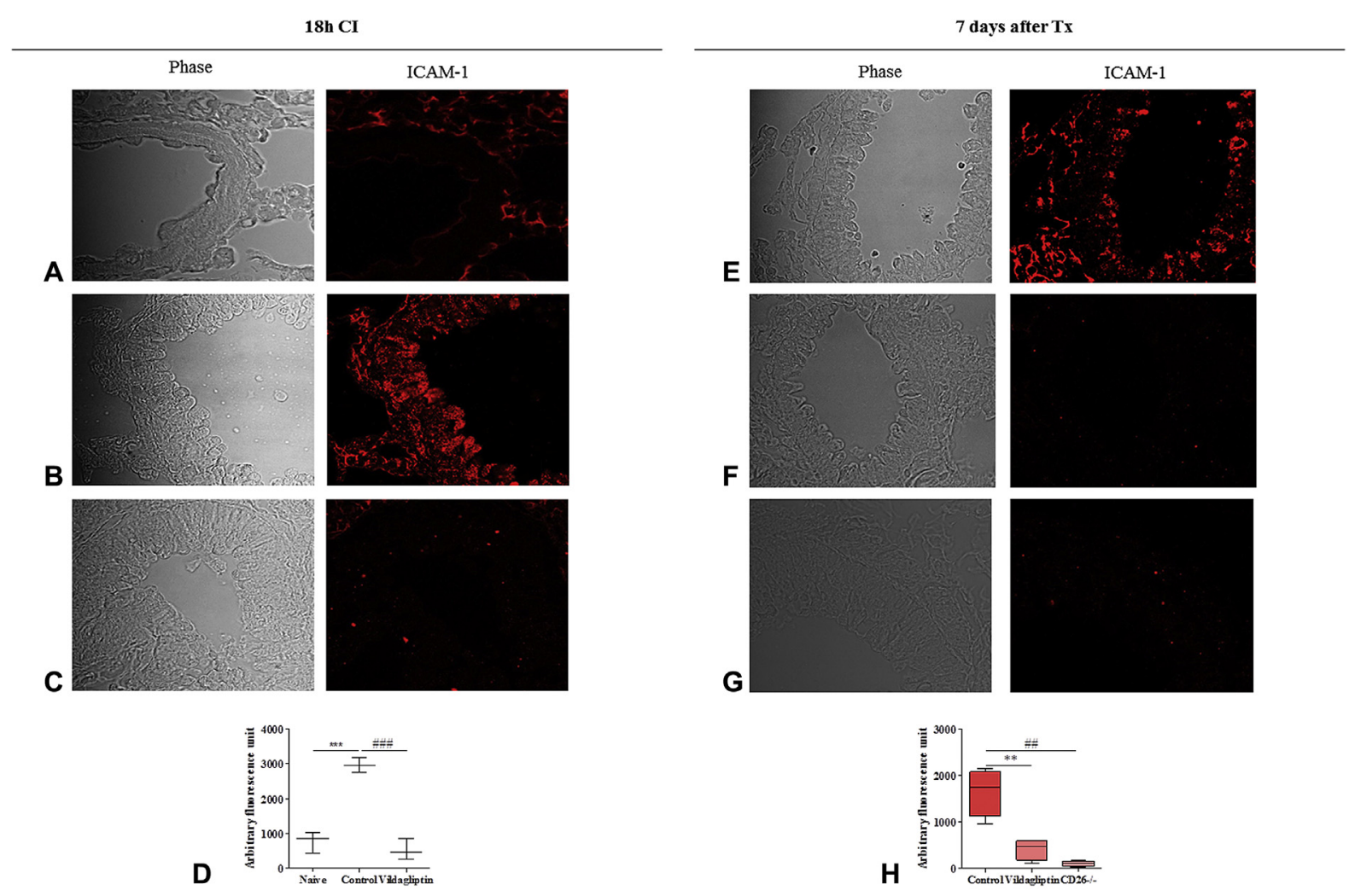

14 days after $T x$
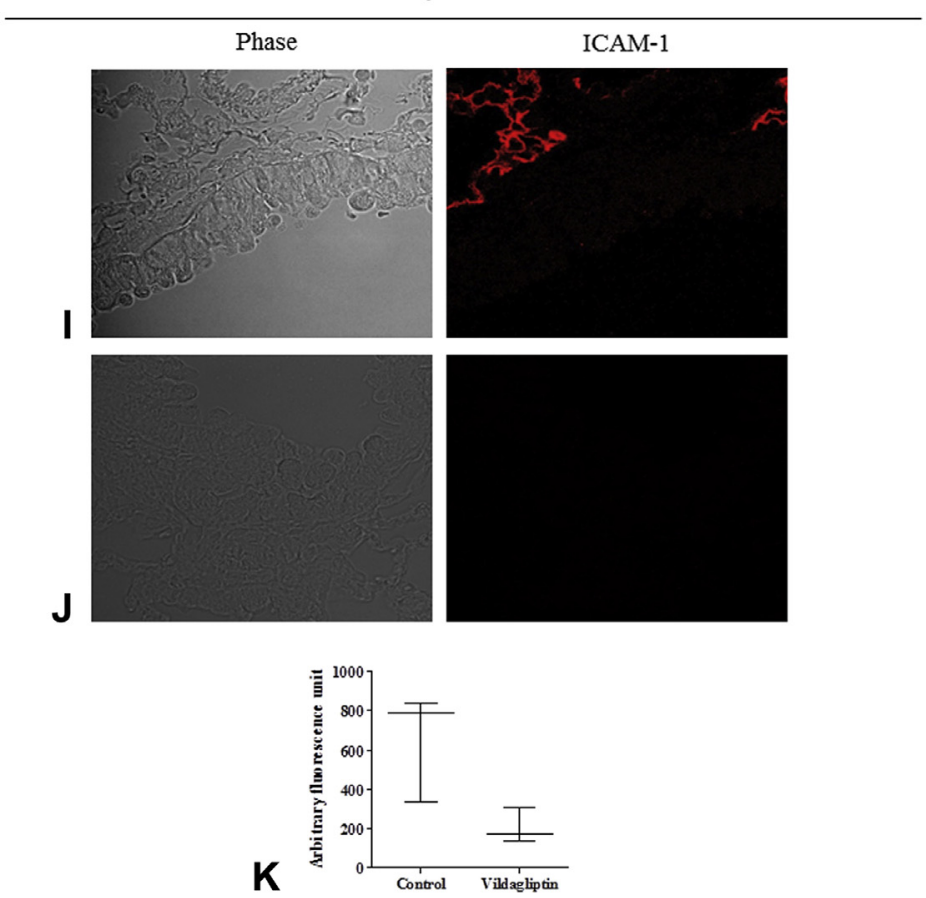

FIGURE 6. ICAM-1 expression in lung sections. The expressions of ICAM-1 in the lungs were significantly different among experimental groups. Compared with the naïve lung (A, D: $\mathrm{n}=3$ ), 18 hours' CI resulted in an elevation of ICAM-1 (B, D: $\mathrm{n}=3$ ) (***P=.0007). Vildagliptin preconditioning $(\mathrm{C}, \mathrm{D}: \mathrm{n}=3$ ) prevented the expression of ICAM-1 during 18 hours' $\mathrm{CI}$ time $(\# \# \#=.004)$. Eighteen hours of CI and 7 days after Tx, the expressions of ICAM-1 was significantly greater in controls $(\mathrm{E}, \mathrm{H}: \mathrm{n}=5)$ compared with the vildagliptin-preconditioned group $(\mathrm{F}, \mathrm{H}: \mathrm{n}=5)$ as well as with the CD26-/ - group $(\mathrm{G}, \mathrm{H}: \mathrm{n}=5)(* * P=.0043, \# \# P=.0037)$. The ICAM-1 expression remained lower through the effect of vildagliptin preconditioning $(\mathrm{J}, \mathrm{K}: \mathrm{n}=3)$ compared with control $(\mathrm{I}, \mathrm{K}: \mathrm{n}=3)$ up to 14 days after Tx $(P=.054)$. Quantitation of the fluorescence staining was carried out by Image $\mathrm{J}$ (National Institutes of Health) analysis software (D, H, K). CI, Cold ischemia; Tx, transplantation; ICAM-1, intercellular adhesion molecule 1. 


\section{Vildagliptin Preconditioning Reduces Short-Term I/ R Injury by Decreased Cell Infiltration}

We tested the effect of vildagliptin preconditioning during the early phase of I/R injury ( 5 hours after lung Tx) on macrophage and neutrophil infiltration, on the expression of ICAM-1 within the graft and on oxygen saturation. The preconditioning by vildagliptin decreased the infiltration of inflammatory cells within the graft 5 hours after Tx. Numbers of macrophages $\left(\mathrm{F} 4 / 80^{+}\right)$(Figure 2, A and $C$ ) and neutrophils $\left(\mathrm{NE}^{+}\right.$) (Figure 2, $B$ and $D$ ) were significantly reduced by vildagliptin preconditioning. Accordingly, the expression of the adhesion molecule ICAM-1 decreased on vildagliptin treatment compared with controls (Figure 2,E). The function of the graft, assessed by oxygen saturation levels $\left(\mathrm{PaO}_{2} / \mathrm{FiO}_{2}\right)$ in the arterial blood, was significantly improved 5 hours after Tx (Figure $2, F$ ). In summary, acute I/R injury was attenuated as the result of reduced numbers of inflammatory cells leading to a better functionality of transplants.

\section{Vildagliptin Preconditioning Induces Improvement From I/R Injury at 7 Days After Tx}

Assessing the lung transplants at a longer time point, namely 7 days, we could observe a slightly shrunken but still ventilated and macroscopically well-preserved transplant. The representative features of the organs show a viable and functioning status after assessing the lung transplants at 7 days of reperfusion on CD26/DPP4inhibition (Figure 3,A) compared with controls showing a red and shrunken appearance (Figure 3, B). Histologically, vildagliptin-treated transplants revealed a well preserved alveolar architecture (Figure 3,C) in contrast to controls in which the alveolar space was collapsed (Figure 3,D); however, vessels and airways were patent and open. Level of oxygen saturation in the arterial blood did not show differences among Tx groups (Figure 3, E).

\section{Vildagliptin Preconditioning Reduces Tx-Related Inflammation 7 and 14 Days After Tx}

Transplants were assessed for macrophages $\left(\mathrm{F} 4 / 80^{+}\right)$, $\mathrm{T}$ cells $\left(\mathrm{CD}^{+}\right)$, B cells $\left(\mathrm{B} 220^{+}\right)$, and neutrophils $\left(\mathrm{NE}^{+}\right)$ at 7 days and 14 days post-Tx. Vildagliptin preconditioned or CD26-/- grafts showed a significantly reduced perivascular macrophage infiltration at 7 days after lung Tx (Figure 4, A). In contrast, there was no difference in alveolar macrophage numbers. Levels of TNF- $\alpha$ in plasma samples of recipients showed that the inhibition of $\mathrm{CD} 26 /$ DPP4 significantly reduced circulating TNF- $\alpha$ levels, which supports the finding of reduced inflammatory cell infiltrates (Figure 4, B). Also, there was a reduced lymphocytic perivascular infiltration of T cells and B cells (Figure E2). This anti-inflammatory effect by CD26/DPP4 inhibition could be observed within grafts up to 14 days after Tx, although to a lesser extent (Figures 5 and E3); however, alveolar lymphocytes and neutrophils were not significantly reduced by CD26/DPP4 inhibition (Figure E4).

\section{The CD26/DPP4 Inhibitor Vildagliptin Reduces ICAM-1 Expression}

Immunofluorescence imaging, carried out in a blinded manner, showed a clear and distinct difference in ICAM-1 expression between naïve lungs and 18-hour CI-injured lungs as well as vildagliptin-preconditioned and CD26-/ - lungs across all the samples evaluated. Specifically, in vildagliptin-preconditioned or $\mathrm{CD} 26-/-$ mice lung sections, ICAM-1 expression was low to absent after 18 hours CI, as well as 7 and 14 days after Tx compared with control specimens (Figure 6, $A-K$ ).

\section{DISCUSSION}

In this study, we showed that experimental preconditioning with the CD26/DPP4 inhibitor vildagliptin provides not only short-term but also intermediate improvement of the ischemia-injured transplanted lungs up to 14 days after Tx. On inhibition by vildagliptin, we found enhanced SDF-1 levels in CI-injured lungs. These elevated SDF-1 levels were paralleled by an increase in IL-10-expressing macrophages. The amelioration of $\mathrm{I} / \mathrm{R}$ injury was maintained by reduced ICAM-1 expression with reduced infiltration of immune cells, mainly macrophages.

It is well known that innate immune cells, such as macrophages and neutrophils, play a key role in $I / R$ injury. ${ }^{11,12}$ Shortly after Tx, vildagliptin preconditioning induced a significant reduction of these cells, paralleled by an improvement of oxygenation in lung transplants. The reasonable explanation for this reduction of cell infiltration were the low to absent expression of ICAM-1 at all time points, the molecule being characteristic for the activation of the endothelial lining and the adhesion and transmigration of cells into the transplanted graft. ${ }^{13,14}$

In general, studies investigating I/R injury show effects after a short period of reperfusion, usually few hours, presuming that these effects persist; however, the current literature does not provide substantial analyses on the function and mechanisms beyond 48 hours. Because I/R injury also contributes to chronic lung allograft dysfunction, long-term results on recovery from primary graft dysfunction seems even more important. Our data demonstrate that even 7 days after Tx, primarily I/Rinjured grafts remain viable over time upon preconditioning with vildagliptin. According to our data, the cause of this long-term functionality of transplanted grafts seems to be related to a reduced-ICAM-1-mediated lower infiltration of immune cells, not only of macrophages, but also of $\mathrm{T}$ cells and B cells, which showed a trend towards continued reduction over time.

Although we used a syngeneic mouse combination for $\mathrm{Tx}, \mathrm{T}$ cells seemed to be involved after Tx. T cells are 
known to have some role in I/R-injury, ${ }^{15}$ however, to a much lesser extent compared with an allogeneic experimental transplant setting. We could recently show that costimulatory blockade of CD26/DPP4 shows evidence that graft-infiltrating $\mathrm{T}$ cells are significantly diminished after treatment with vildagliptin. ${ }^{16}$ Despite the lack of alloantigen in this study, it is well imaginable that the inhibition of the co-stimulatory activity of CD26/DPP4 is triggered by the $\mathrm{I} / \mathrm{R}$ injury and thus contributed in part to the reduction of T-cell infiltrations.

We deem that the short-term as well as the intermediate graft amelioration is related to the effect initiated by the preconditioning of the graft: intragraft inhibition by vildagliptin leads to decreased SDF-1 degradation, thereby enhancing the protein concentration within the organ. SDF-1 is a substrate of CD26/DPP4 and has been shown to exert regenerative effects through various mechanisms in ischemic organs. ${ }^{17}$ Zaruba and colleagues ${ }^{18}$ and Theiss and colleagues ${ }^{19}$ could show that a combination of DPP4 inhibition and administration of granulocyte-colony stimulating factor mediated cardiac regeneration through the SDF-1/CXCR4-axis. Our own group showed that increased levels of SDF-1 lead to a recruitment of regenerative $\mathrm{CD} 34^{+}$stem cells, resulting in a recovery of $\mathrm{I} / \mathrm{R}$ injured grafts up to 48 hours after experimental mouse lung Tx via inhibition of CD26/DPP4 of the recipient, ${ }^{8}$ thus corroborating these results.

Beside the reduction of immune cells over time, another mechanism we propose here for the long-term recovery of I/R lung injury is that SDF-1 activates alternative (M2) rather than classical (M1) macrophages and thereby create an immune-protective milieu. There is evidence that CXCR4-positive macrophages polarize towards a M2 phenotype via the SDF-1/CXCR4-axis. ${ }^{20}$ These macrophages seem to be important for regulating the inflammatory response. ${ }^{21}$ Others have equally shown that SDF-1 production modulates the differentiation of monocytes toward immunosuppressive functions. ${ }^{22}$ In line with these data, we could show by FACS analysis that macrophages produced IL-10, which reflects an alternative macrophage phenotype that exerts anti-inflammatory effects. This anti-inflammatory effect of IL-10 has been proven in septic conditions with endothelial leakage thereby attenuating injury, ${ }^{23}$ but also downregulating posttransplant immune responses after orthotopic lung Tx. ${ }^{24,25}$ Other than macrophages, inducible regulatory $\mathrm{T}$ cells can be well responsible for IL-10 production as recently shown in mouse lung allograft rejection. ${ }^{26}$

The decreased levels of TNF- $\alpha$ that we measured in engrafted organs additionally support the hypothesis that either classical macrophages were attenuated or alternative macrophages were activated, presumably also by increased levels of IL-10. In vitro analysis confirmed that increasing concentrations of SDF-1 were able to dampen the TNF- $\alpha$ secretion from macrophages (cell line RAW 264.7).

The mechanistic observations proposed here were based on the analysis of 18 hours' CI transplants. A potential drawback of this study is that we did not investigate these findings after reperfusion, for instance, if the presence of IL- $10^{+}$macrophages persisted over time. Also, we could not find SDF-1 levels to be elevated during the 7-day experimental follow-up. CD26/DPP4 inhibition, however, seems to be effective in the preconditioning phase and induces prolonged effects through the expression of SDF-1, which was found to be increased immediately after $\mathrm{CI}$ and which seems to be sufficient to elicit long-term effects. Another obstacle was the impossibility to obtain reliable oxygenation data from I/R-injured control grafts after 18 hours of ischemia and 7 days of reperfusion. First, by taking systemic arterial blood draw, the function of both lungs was evaluated. We tried to overcome this hurdle by subtracting the oxygenation values of a naive mouse from a Tx recipient mouse. Second, from the appearance of at least some of the transplanted lungs, it is likely that the systemic arterial blood gas is measuring primarily the function of the naive lung, which falsifies an objective oxygenation measurement. This should be regarded as an important confounder.

A major advantage in our experimental approach of preconditioning of lung transplants by vildagliptin is that this CD26/DPP4 inhibitor is in safe clinical use as a long-term treatment of type 2 diabetes. ${ }^{27}$ This makes vildagliptin an attractive compound for a further investigation for clinical studies.

\section{Conflict of Interest Statement}

Authors have nothing to disclose with regard to commercial support.

\section{References}

1. Abbott CA, Baker E, Sutherland GR, McCaughan GW. Genomic organization, exact localization, and tissue expression of the human CD26 (dipeptidyl peptidase IV) gene. Immunogenetics. 1994;40:331-8.

2. Tanaka T, Camerini D, Seed B, Torimoto Y, Dang NH, Kameoka J, et al. Cloning and functional expression of the $\mathrm{T}$ cell activation antigen CD26. J Immunol. 1992;149:481-6

3. Waumans Y, Baerts L, Kehoe K, Lambeir AM, De Meester I. The dipeptidyl peptidase family, prolyl oligopeptidase, and prolyl carboxypeptidase in the immune system and inflammatory disease, including atherosclerosis. Front Immunol. 2015;6:387.

4. Tanaka T, Duke-Cohan JS, Kameoka J, Yaron A, Lee I, Schlossman SF, et al Enhancement of antigen-induced T-cell proliferation by soluble CD26/ dipeptidyl peptidase IV. Proc Natl Acad Sci USA. 1994;91:3082-6.

5. Zhai W, Jungraithmayr W, De Meester I, Inci I, Augustyns K, Arni S, et al. Primary graft dysfunction in lung transplantation: the role of CD26/ dipeptidylpeptidase IV and vasoactive intestinal peptide. Transplantation. 2009;87:1140-6

6. Baerts L, Waumans Y, Brandt I, Jungraithmayr W, Van der Veken P, Vanderheyden M, et al. Circulating stromal cell-derived factor 1alpha levels in heart failure: a matter of proper sampling. PLoS One. 2015;10:e0141408.

7. Campbell TB, Broxmeyer HE. CD26 inhibition and hematopoiesis: a novel approach to enhance transplantation. Front Biosci. 2008;13:1795-805. 
8. Jungraithmayr W, De Meester I, Matheeussen V, Baerts L, Arni S, Weder W. CD26/DPP-4 inhibition recruits regenerative stem cells via stromal cell-derived factor-1 and beneficially influences ischaemia-reperfusion injury in mouse lung transplantation. Eur J Cardiothorac Surg. 2012;41:1166-73.

9. Jungraithmayr WM, Korom S, Hillinger S, Weder W. A mouse model of orthotopic, single-lung transplantation. J Thorac Cardiovasc Surg. 2009;137: 486-91.

10. Jungraithmayr W, Codarri L, Bouchaud G, Krieg C, Boyman O, Gyülvészi G, et al. Cytokine complex-expanded natural killer cells improve allogeneic lung transplant function via depletion of donor dendritic cells. Am J Respir Crit Care Med. 2013;187:1349-59.

11. Naidu BV, Krishnadasan B, Farivar AS, Woolley SM, Thomas R, Van Rooijen N, et al. Early activation of the alveolar macrophage is critical to the development of lung ischemia-reperfusion injury. J Thorac Cardiovasc Surg. 2003;126:200-7.

12. den Hengst WA, Gielis JF, Lin JY, Van Schil PE, De Windt LJ, Moens AL. Lung ischemia-reperfusion injury: a molecular and clinical view on a complex pathophysiological process. Am J Physiol Heart Circ Physiol. 2010;299:H1283-99.

13. Brunner E, Lehle K, Hirt SW, Schmid C, von Suesskind-Schwendi M Everolimus's influence on persistent acute rejection after experimental lung transplantation. Adv Clin Exp Med. 2013;22:355-9.

14. Lu YT, Chen PG, Liu SF. Time course of lung ischemia-reperfusion-induced ICAM-1 expression and its role in ischemia-reperfusion lung injury. $J$ Appl Physiol (1985). 2002;93:620-8.

15. Linfert D, Chowdhry T, Rabb H. Lymphocytes and ischemia-reperfusion injury. Transplant Rev (Orlando). 2009;23:1-10.

16. Yamada Y, Jang JH, De Meester I, Baerts L, Vliegen G, Inci I, et al. CD26 costimulatory blockade improves lung allograft rejection and is associated with enhanced interleukin-10 expression. J Heart Lung Transplant. 2016;35:508-17.

17. Matheeussen V, Jungraithmayr W, De Meester I. Dipeptidyl peptidase 4 as a therapeutic target in ischemia/reperfusion injury. Pharmacol Ther. 2012;136: 267-82.

18. Zaruba MM, Theiss HD, Vallaster M, Mehl U, Brunner S, David R, et al. Synergy between CD26/DPP-IV inhibition and G-CSF improves cardiac function after acute myocardial infarction. Cell Stem Cell. 2009;4:313-23.
19. Theiss HD, Vallaster M, Rischpler C, Krieg L, Zaruba MM, Brunner S, et al. Dual stem cell therapy after myocardial infarction acts specifically by enhanced homing via the SDF-1/CXCR4 axis. Stem Cell Res. 2011;7:244-55.

20. Beider K, Bitner H, Leiba M, Gutwein O, Koren-Michowitz M, Ostrovsky O, et al. Multiple myeloma cells recruit tumor-supportive macrophages through the CXCR4/CXCL12 axis and promote their polarization toward the M2 phenotype. Oncotarget. 2014;5:11283-96.

21. Tysseling VM, Mithal D, Sahni V, Birch D, Jung H, Belmadani A, et al. SDF1 in the dorsal corticospinal tract promotes CXCR4+ cell migration after spinal cord injury. J Neuroinflammation. 2011;8:16.

22. Sanchez-Martin L, Estecha A, Samaniego R, Sanchez-Ramon S, Vega MA, Sanchez-Mateos P. The chemokine CXCL12 regulates monocytemacrophage differentiation and RUNX3 expression. Blood. 2011;117:88-97.

23. Fan H, Goodwin AJ, Chang E, Zingarelli B, Borg K, Guan S, et al. Endothelial progenitor cells and a stromal cell-derived factor-1alpha analogue synergistically improve survival in sepsis. Ame J Respir Crit Care Med. 2014; 189:1509-19.

24. Fischer S, De Perrot M, Liu M, MacLean AA, Cardella JA, Imai Y, et al. Interleukin 10 gene transfection of donor lungs ameliorates posttransplant cell death by a switch from cellular necrosis to apoptosis. J Thorac Cardiovasc Surg. 2003;126:1174-80.

25. Hirayama S, Sato M, Loisel-Meyer S, Matsuda Y, Oishi H, Guan Z, et al. Lentivirus IL-10 gene therapy down-regulates IL-17 and attenuates mouse orthotopic lung allograft rejection. Am J Transplant. 2013;13: 1586-93.

26. Zhou W, Zhou X, Gaowa S, Meng Q, Zhan Z, Liu J, et al. The critical role of induced CD4 + FoxP3 + regulatory cells in suppression of interleukin-17 production and attenuation of mouse orthotopic lung allograft rejection. Transplantation. 2015;99:1356-64.

27. Holst JJ, Deacon CF. Inhibition of the activity of dipeptidyl-peptidase IV as a treatment for type 2 diabetes. Diabetes. 1998;47:1663-70.

Key Words: CD26/DPP4, mouse lung transplantation, SDF-1, macrophages, IL-10, ICAM-1 


\section{$\mathrm{CD}^{+}$}



NKp46

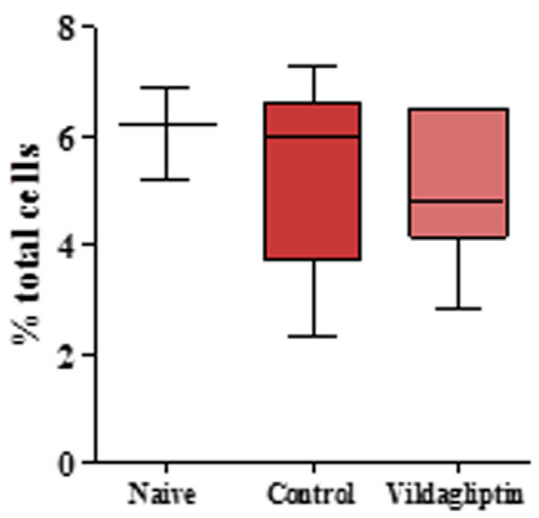

$\mathrm{CD8}^{+}$



$\mathrm{F} 4 / 80^{+}$

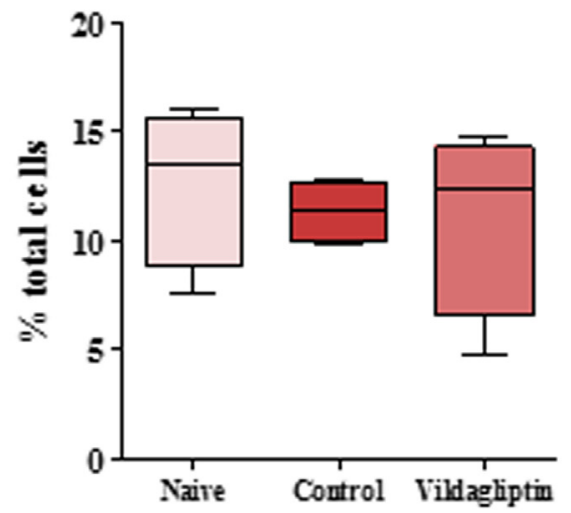

FIGURE E1. Effect of 18 hours of CI on pulmonary immune cells with and without vildagliptin preconditioning. Total numbers of $\mathrm{CD}^{+}, \mathrm{CD}^{+}, \mathrm{NKp}^{+} 6^{+}$, and $\mathrm{F} 4 / 80^{+}$cells showed no significant difference by FACS analysis (naïve $[\mathrm{n}=3]$, control $[\mathrm{n}=4]$, vildagliptin $[\mathrm{n}=4]$ ). 


\section{7 days after $\mathbf{T x}$}
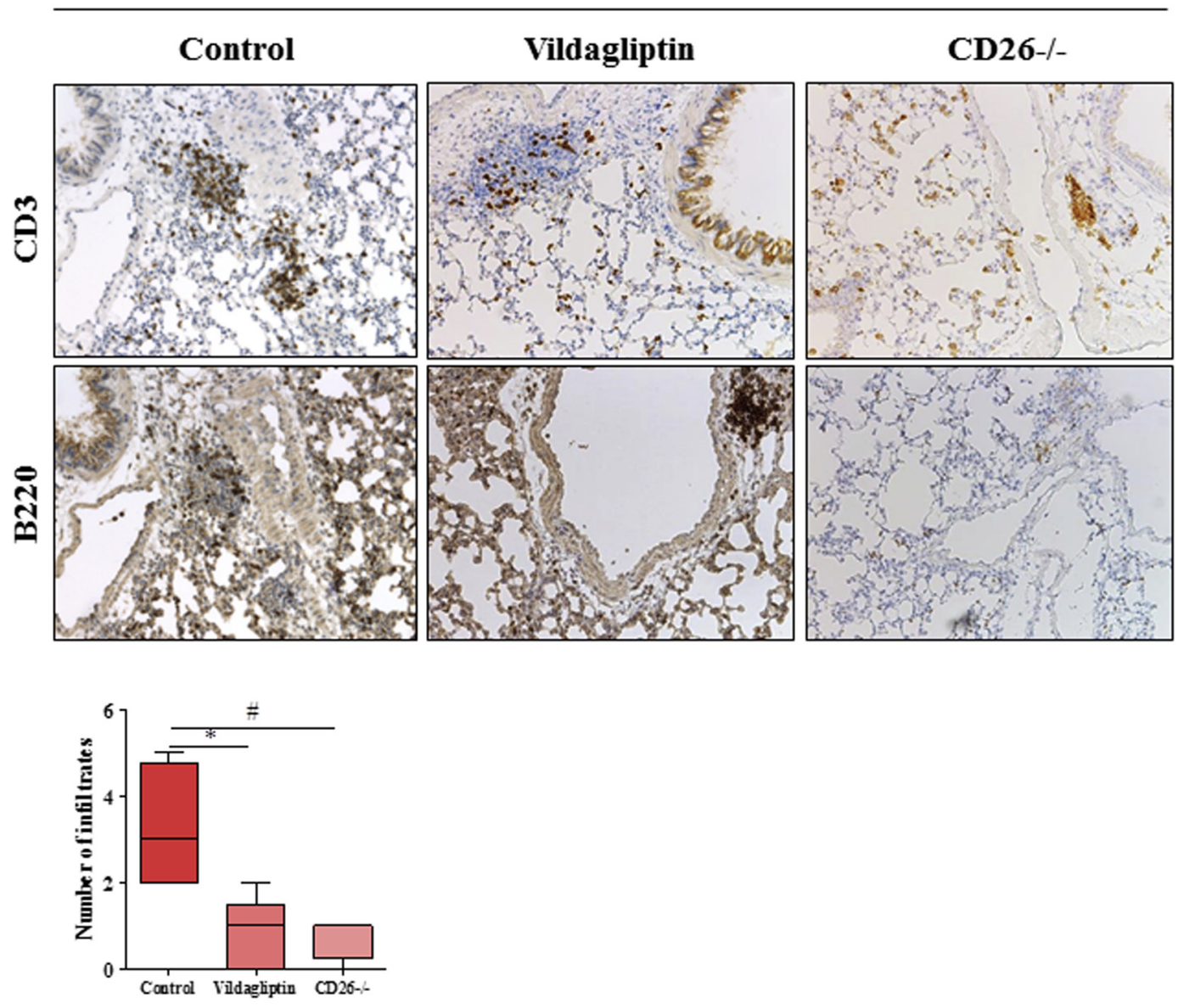

Lymphocyte infiltration

FIGURE E2. Decreased lymphocyte numbers within the graft through CD26/DPP4-inhibition. The number of perivascular CD $3^{+}$and B220 $0^{+}$lymphocytes were consistently reduced in CD26/DPP4-inhibited and CD26/DPP4-/- grafts 7 days after Tx (control [n $=5$ ], vildagliptin [n $=5]$, CD26-/ - [n $=4]$ $* P=.067, \# P=.0195) . T x$, Transplantation; $C D 26 / D P P 4$, cluster of differentiation 26/dipeptidylpeptidase 4 . 
CD3



F 4/80



B220

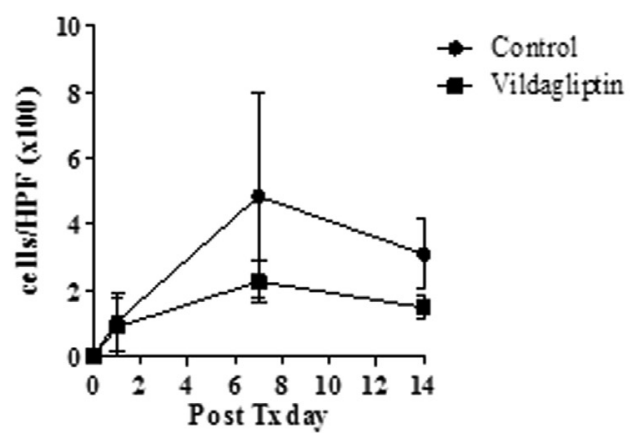

NE

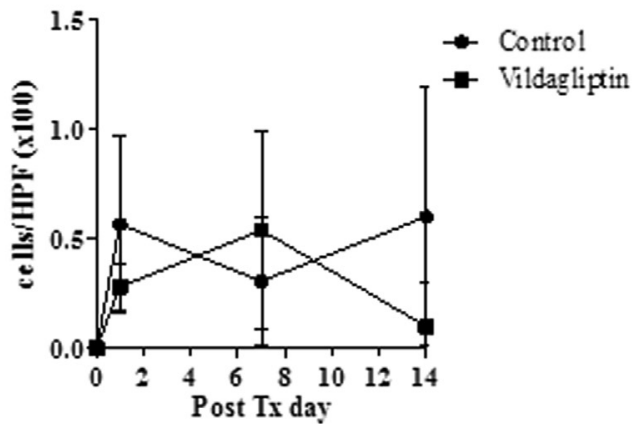

FIGURE E3. Time course of perivascular infiltration by immune cells 5 hours, 7 days, and 14 days after mouse lung Tx. Overall, the numbers of T-cells $\left(\mathrm{CD}^{+}\right)$, B cells $\left(\mathrm{B22O}^{+}\right)$, and macrophages $\left(F 4 / 8 \mathrm{O}^{+}\right)$showed a trend towards lower levels in vildagliptin-preconditioned transplants. $T x$, Transplantation. 


\section{7 days after $T x$}

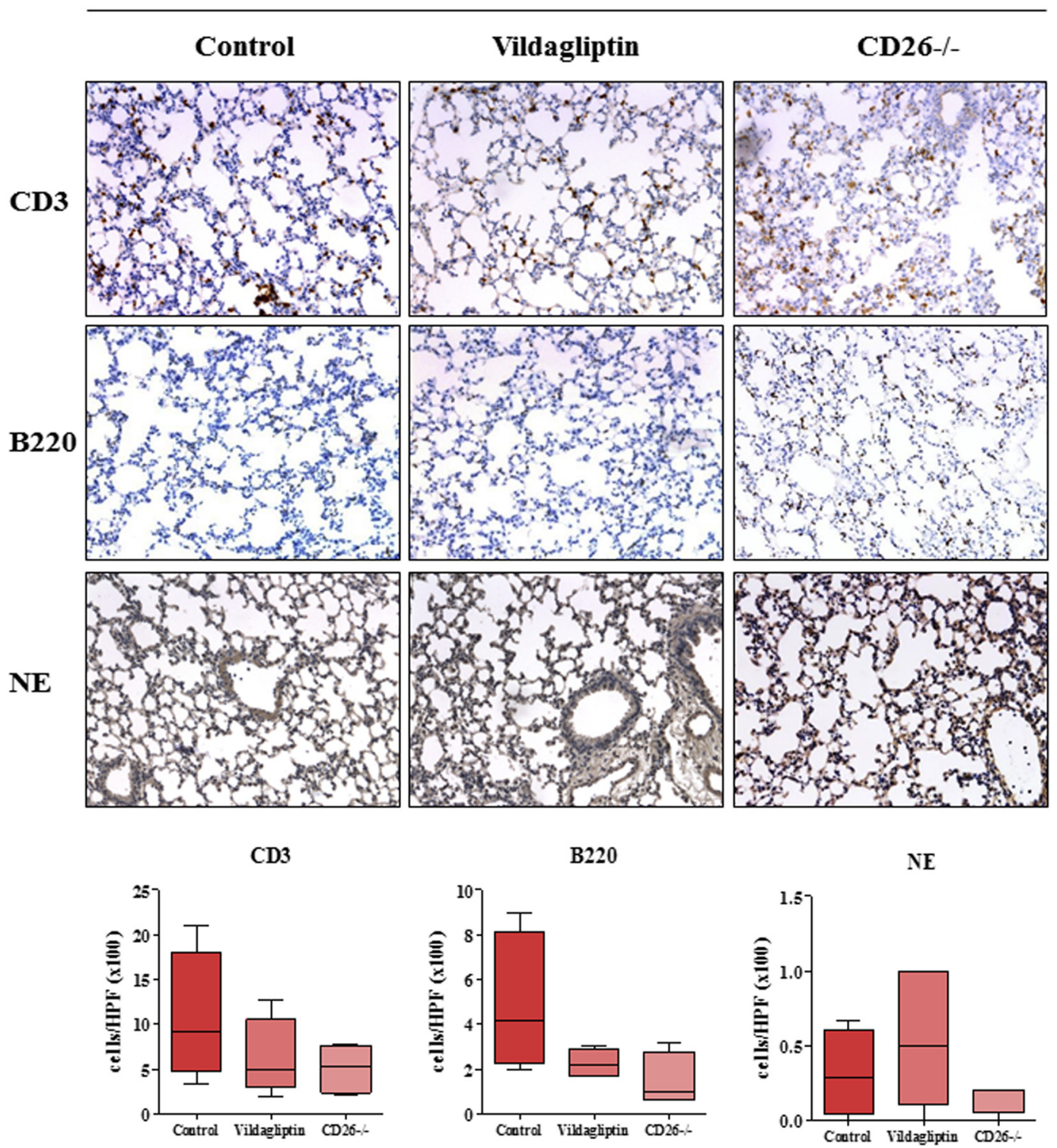

FIGURE E4. Infiltrating lymphocytes in the alveolar space of transplants 7 days after Tx. Immunohistochemistry of CD3, B220, and NE showed a reduced but not significant change of infiltrating lymphocytes by CD26/DPP4-inhibition (control $[\mathrm{n}=5]$, vildagliptin $[\mathrm{n}=5]$, CD26-/- $[\mathrm{n}=4]$ ). $T x$, Transplantation; NE, neutrophil elastase; CD26/DPP4, cluster of differentiation 26/dipeptidylpeptidase 4. 